\title{
Oodinium jordani n. sp., a dinoflagellate (Dinoflagellata: Oodinidae) ectoparasitic on Sagitta elegans (Chaetognatha)
}

\author{
Norman McLean ${ }^{1}$, Claus Nielsen ${ }^{2}$ \\ ${ }^{1}$ Department of Biology, San Diego State University, San Diego, California 92182-0057, USA \\ ${ }^{2}$ Zoologisk Museum, University of Copenhagen, Universitetsparken 15, DK-2100 Copenhagen $\varnothing$, Denmark
}

\begin{abstract}
The ectoparasitic dinoflagellate Oodinium jordani n. sp. is reported from Sagitta elegans (Phylum Chaetognatha). The trophozoite of $O$. jordani, usually attached to a fin of the host, reaches $394 \mu \mathrm{m}$ in length; its peduncular bulb is divided into a proximal and a distal portion by a transverse constriction. The short peduncular cortex bears longitudinal ridges; the peduncular medulla penetrates the host and produces an extensive lesion, and ends in vase-like invaginations rarely joined with membranous channels. The trophozoite drops from the host and divides, at which time chromosomes, many nucleoli and 2 archoplasmic masses can be distinguished with light microscopy. The chromosomes do not resemble those characteristic of dinoflagellates until the 9th division, when transmission electron microscopy reveals a stage in the formation of dinokaryotic chromosomes. Lipid droplets, paraglycogen-like granules and trichocysts characteristic of dinoflagellates are present. This is the first report of a dinoflagellate ectoparasitic on a chaetognath.
\end{abstract}

\section{INTRODUCTION}

Except for a dinoflagellate hyperparasitic in an intestinal ciliate, parasitic dinoflagellates have not been reported in association with the phylum Chaetognatha (Cachon \& Cachon 1987). We have observed an ectoparasitic dinoflagellate, that we describe as a new species, on the chaetognath Sagitta elegans Verrill, 1873, from northwest Washington, USA.

\section{MATERIALS AND METHODS}

Eleven Sagitta elegans bearing one or more ectoparasitic dinoflagellate trophozoites were collected in August 1988 from surface water or from a depth of ca $50 \mathrm{~m}$ in the vicinity of the Friday Harbor Laboratories, San Juan Island, Washington, USA; they were maintained on seawater tables $\left(\mathrm{ca} 11^{\circ} \mathrm{C}\right.$ ) at the laboratories.

Parasites were prepared for examination in situ, or were allowed to drop from the host and to divide before fixation and preparation for light microscopy (LM), transmission electron microscopy (TEM), or scanning electron microscopy (SEM). For LM and TEM, trophozoites and cells produced by the $1 \mathrm{st}, 3 \mathrm{rd}, 5$ th and 8th divisions were fixed in $3 \%$ glutaraldehyde (Ladd) in $0.1 \mathrm{M}$ phosphate buffer ( $\mathrm{pH} 7.3$ ) with $0.35 \mathrm{M}$ sucrose (room temp., $1 \mathrm{~h}$ ), rinsed briefly in buffer with sucrose, and postfixed on ice in $1 \%$ osmium tetroxide in $0.1 \mathrm{M}$ phosphate buffer ( $\mathrm{pH} 7.3$ ) with $0.35 \mathrm{M}$ sucrose (1 h). Cells produced by the 9 th division were fixed in $1 \%$ osmium tetroxide in equal parts of sea water and $0.2 \mathrm{M}$ phosphate buffer with $0.7 \mathrm{M}$ sucrose on ice $(1 \mathrm{~h})$. Specimens for sectioning were dehydrated in an acetone series and embedded in Spurr's medium (Ladd). For $\mathrm{LM}, 1 \mu \mathrm{m}$ sections were stained in $1 \%$ methylene blue in $1 \%$ borax. For TEM, silver sections were stained in saturated aqueous uranyl acetate for $12 \mathrm{~min}$, and in $0.1 \%$ lead citrate for $3 \mathrm{~min}$; they were examined with a Philips 300 electron microscope.

For SEM, specimens fixed in $2 \%$ osmium tetroxide in distilled water were dehydrated in an acetone series and critical-point dried in $\mathrm{CO}_{2}$. They were attached to stubs with Double Stick Scotch Tape, coated with Pd and examined with a JEOL JSM-35 scanning electron microscope.

Measurements of parasites were made on fixed, embedded specimens. 


\section{RESULTS}

\section{Oodinium jordani n. sp. (Figs. 1 to 17 )}

Diagnosis. Trophozoites oval, l $=125$ to $394 \mu \mathrm{m}, \mathrm{w}=$ 47 to $243 \mu \mathrm{m}$. Nucleus large, oval; chromosomes not visible; cytoplasm contains lipid droplets and paraglycogen-like granules; peduncular bulb constricted centrally, densely provided with membranous channels and limited distally by an osmiophilic ring; short peduncular cortex provided with longitudinal ridges; peduncular medulla penetrates host and terminates in many vase-like structures formed from 2 membranes and rarely joined with membranous channels. Cleavage of the trophozoite is longitudinal; after 9 divisions, a stage in the formation of dinokaryotic chromosomes is visible. Trichocysts present. Host, Sagitta elegans Verrill, 1873 (Phylum Chaetognatha).

Type locality. Marine. Surface waters to approximately $50 \mathrm{~m}$ near San Juan Island, Washington, USA, Lat. $48^{\circ} 32^{\prime} \mathrm{N}$, Long. $123^{\circ} 00^{\prime} \mathrm{W}$.

Type material. Syntypes: trophozoites embedded in epoxy resin have been deposited at the National Protozoan Type Collection, National Museum of Natural History, Smithsonian Institution, Washington, D.C., and given the registration numbers: USNM 41713 , 41714 and 41715 .

Etymology. The species is named in recognition of the indefatigable Christopher Jordan, whose collecting efforts contributed greatly to this study.

\section{Morphology, activities and division of the parasite}

The trophozoites (Figs. 1 and 2) were attached to the fin of Sagitta elegans, or less frequently to the body itself, by a peduncle, the short cortical portion of which was densely provided with longitudinal ridges (Fig. 3). Some of the hosts were damaged during collection, and a few of the trophozoites dropped from these after about $1 \mathrm{~d}$. This liberation could also be induced by excising portions of the host.

Trophozoites were oval in shape (Figs. 1 and 2), and easily visible with the unaided eye. The lower portion bore a tesselation (Fig. 3) that possibly reflected the mosaic structure of the theca commonly seen in dinoflagellates. Larger parasites were yellow; the smaller, presumably younger, specimens were white. A mombranous cytoplasm containing many Golgi bodies and mitochondria surrounded the large oval nucleus, and extended outward to the cell wall in dendritic projections (Fig. 2) that alternated with a granular cytoplasm containing lipid droplets and paraglycogen-like granules. The nucleus contained a flocculent, granular nucleoplasm and many small basophilic bodies; chromosomes were not identifiable.

Below the nucleus, proceeding toward the host, membranous cytoplasmic channels converged on an elongate aperture (Figs. 2 and 4 ) that broadened into a peduncular bulb (Figs. 2, 4 and 5). This organelle was divided into a proximal and a distal portion by a transverse constriction (Figs, 2 and 5). The proximal portion contained large numbers of channels, each of which was bounded by 2 membranes (Fig. 6); in the distal portion, the number of membranous channels descending from the proximal portion was greatly reduced. A dense, osmiophilic ring (Figs. 2 and 7 ) marked the lower end of the peduncular bulb, and the upper end of the peduncle.

Beginning at the osmiophilic ring and proceeding outward to terminate at a secondary osmiophilic ring was an electron-lucent, finely fibrous rim or bourrelet (Fig. 7) that encircled the upper portion of the peduncle. The secondary osmiophilic ring (Figs. 2 and 7) was the terminus of the cellular theca (Fig. 7), and was composed of several spatulate, finger-like projections. The peduncle was composed of a thick granular cortex, and a more finely granular medulla (Fig. 7) that contained very few channels bounded by 1 or 2 membranes, and that extended into the host. The terminal surface of the peduncular medulla was formed from 2 membranes, and was invaginated to form many vaselike structures (Fig. 8) that were rarely joined with membranous channels. The terminal peduncular surface was not a sucking disk, but a penetrating organelle that produced a lesion, containing the medulla, that extended laterally through the tissue of the host over $80 \mathrm{um}$ from the point of attachment causing considerable damage (Fig. 9). Usually the pronounced erosion of tissue halted at the basement mem-

Figs. 1 to 6. Oodinium jordani. Fig. 1. SEM; trophozoite attached to fin (f) of Sagitta elegans by peduncle; scale bar: 100 um. Fig. 2. LM; section through trophozoite attached to fin (f) of $S$. elegans; note membranous cytoplasm (") surrounding nucleus (n) and proceeding outward from it in dendritic projections that alternate with granular cytoplasm (g), aperture (aj leading into proximal portion of peduncular bulb ( $p$ ), transverse constriction (between arrows) between proximal and distal portion of peduncular bulb, osmiophilic ring (arrowhead) and secondary osmiophilic ring (arrow); scale bar: $100 \mu \mathrm{m}$. Fig. 3 . SEM; portion of Fig. 1 at higher magnification, showing densely ridged peduncular cortex and fine tesselation (arrowheads); scale bar: 10 um. Fig. 4. TEM; aperture (a) containing many membranous channels descending into proximal portion of peduncular bulb (p): scale bar: 5 um. Fig. 5. TEM; transverse constriction (between arrows) between proximal portion of peduncular bulb (p) and distal portion of peduncular bulb; scale bar: $5 \mu \mathrm{m}$. Fig. 6 . TEM; membranous channels, each of which bounded by 2 menbranes (arrowheads), in the proximal portion of the peduncular bulb; scale bar: $0.54 \mathrm{~m}$ 

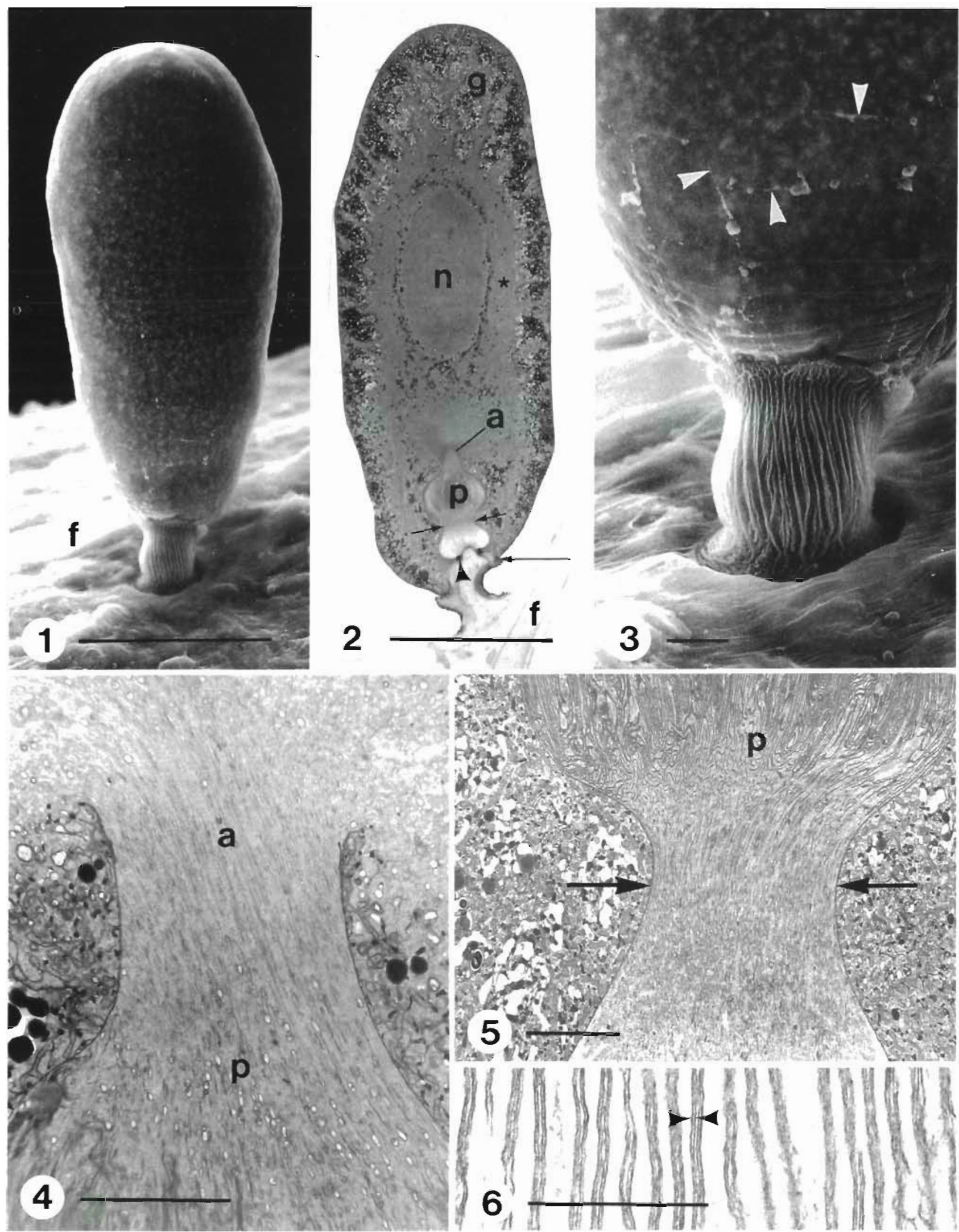
brane, the central skeletal support of the fin (Fig. 10). In one instance (Fig. 9) the basement membrane itself had been destroyed, and the opposite surface of the fin was invaded.

About $2 \mathrm{~d}$ after separation from the host, the parasites divided into 2 cells; after $4 \mathrm{~d}$ most of them had divided up to 9 times. A fine, hyaline membrane was shed at the beginning of each cell division. The first division (i.e. the cleavage of the trophozoite) was longitudinal. Cytokinesis commenced at the end of the trophozoite opposite the peciuncle. The nucleus divided before the cytoplasmic furrows reached the nuclear level. Chromosomes were not identified in the trophozoite nucleus, but were visible by LM (Fig. 11) after the nucleus had divided, as were putative nucleoli; in TEM, however, chromosomes wele seeri only as amorphous granular masses slightly more dense than the surrounding granular nucleoplasm. Distally, each daughter nucleus was separated from the cell wall by a distinct layer of membranous cytoplasm or archoplasm (Fig. 11) well provided with numerous mitochondria. After 8 divisions (Fig. 12), a small group of dense chromosomes could be seen by LM, but only after 9 divisions could forming dinokaryotic chromosomes be distinguished by TEM (Fig. 13). Flagella were not seen in cells produced by the 9 th division.

A pusular system (Fig. 9) of short membranous figures emptying into a broad channel or ampulla (Fig. 14) debouched near the lower end of the peduncular bulb of the trophozoite. Trichocysts with an electronopaque core that had a conical head and a group of filaments extending from the head to several dense plaques near the outer region of the parasite (Fig. 15), a limiting membrane bearing hoops (Fig. 16), and a longitudinal periodicity within the core (Fig. 17), were present in all stages examined.

\section{DISCUSSION}

The new species described above clearly belongs to the parasitic dinoflagellate genus Oodinium (Chatton 1912) in which 4 species have hitherto been recognized
(Cachon \& Cachon 1987). Only 1 comprehensive account of Oodinium trophozoite morphology (Cachon \& Cachon 1971) is available for comparison with the present study.

The trophozoite of Oodinium fritillariae Chatton, 1912, parasitic on an appendicularian tunicate in the Mediterranean Sea, is quite similar to the Sagitta elegans parasite. There are, however, 3 significant ultrastructural differences. First, the transverse constriction of the peduncular bulb, evident in the present species is lacking in O. fritillariae (Chatton 1912, p. 87, Fig. 2 Cachon \& Cachon 1971). In that organism, membranous channels originating near the nucleus converge on an aperture that leads into the single dilation of the peduncular bulb, defined distally by the osmiophilic ring. In $O$. fritillariae, therefore, there is a single bulbous enlargement of the membranous channel system. whereas in this study, there are two. Second, the sole or end of the peduncle of $O$. fritillariae is a sucking disk in contrast, the peduncle described here penetrates the host, and has pronounced histolytic properties. Third, the vase-like structures of the peduncular sole in $O$. fritillariae typically are joined with distinct channels, unlike the $S$. elegans parasite.

Little specific morphological information has been found on Oodinium acanthometrae Cachon, 1964 (Cachon 1964, p. 7, 95 to 96; Cachon et al. 1970, p.471, footnote), a parasite of acantharians (Actinopoda) in the Mediterranean Sea.

Oodinium dogieli (Dogiel, 1910) Cachon \& Cachon, 1971 (Cachon \& Cachon 1971, p. 154, footnote), parasitic on annelids in the Mediterranean Sea, has been shown with clarity to possess a single bulbous enlargement of the membranous channel system (Dogiel 1910, Plate XIV, Fig. 41), as is the case in O. fritillariae.

In constrast, 2 distinctive bulbous dilations were shown unequivocally (Hovasse 1935, Plate II, Fig. 12) to be present in Oodinium poucheti (Lemmerman, 1899) Chatton, 1912, a parasite on the tail of the appendicularian tunicate Oikopleura dioica in the Mediterranean Sea. Furthermore, the peduncle penetrates the host (Chatton 1920), as in the species of the present study. The longitudinal cortical ridges in the peduncle of the

Figs. 7 to 17 . Oodinium jordani. Fig. 7. TEM; distal portion of peduncular bulb (d), osmiophilic ring (arrowheads), bourrelet (b), secondary osmiophilic ring (arrow), theca (t), peduncular cortex (c) and medulla (m); scale bar 2 um. Fig. 8 . TEM; vase-like structures formed by invagination of the 2 membranes (arrowhead) that form the terminal surface of the peduncular medulla; $\mathrm{h}$ : host basement membrane; m: peduncular medulla; scale bar: $0.2 \mu \mathrm{m}$. Fig. 9 . LMi portion of trophozoite attached to host fin; arrowheads indicate extent of lesion caused by histolytic peduncle within fin; arrow: site of destruction of host basement membrane; pu: pusule; scale bar: $100 \mu \mathrm{m}$. Fig. 10. TEM; terminal surface of peduncular medulla applied to host basement membrane $(\mathrm{h})_{\text {; }}$ note line of vase-like structures that mark end of medulla; $\mathrm{r}$ : host fin ray; m: peduncular. medulla; scale bar: 5 um. Fig. 11. LM; first division of a trophozoite; $\mathrm{a}^{\prime}$ : archoplasm; $\mathrm{n}$ : nucleus; arrowheads: chromosomes; dense bodies within nuclei are nucleoli; scale bar: $20 \mu \mathrm{m}$. Fig. 12. LM; cell produced by 8 th division; arrow: chromosome; scale bar: 10 $1 \mathrm{~mm}$. Fig. 13. TEM; stage in formation of dinokaryotic chromosomes (ch) in cell produced by 9 th division; scale bar $1 \mathrm{\mu m}$. Fig. 14. TEMi pusule in trophozoite. a". ampulla; scale bar: $0.5 \mu \mathrm{m}$. Fig. 15 . TEM; trichocyst with electron-opaque core that has a conical head and a group of filaments extending to several dense plaques (arrowhead); scale bar $0.2 \mu \mathrm{m}$. Fig. 16. TEM; trichocyst showing hoops (arrowheads); scale bar: $0.1 \mu \mathrm{m}$. Fig. 17. TEM, trichocyst showing longitudinal periodicity within the core; scale bar: $0.1 \mathrm{um}$ 

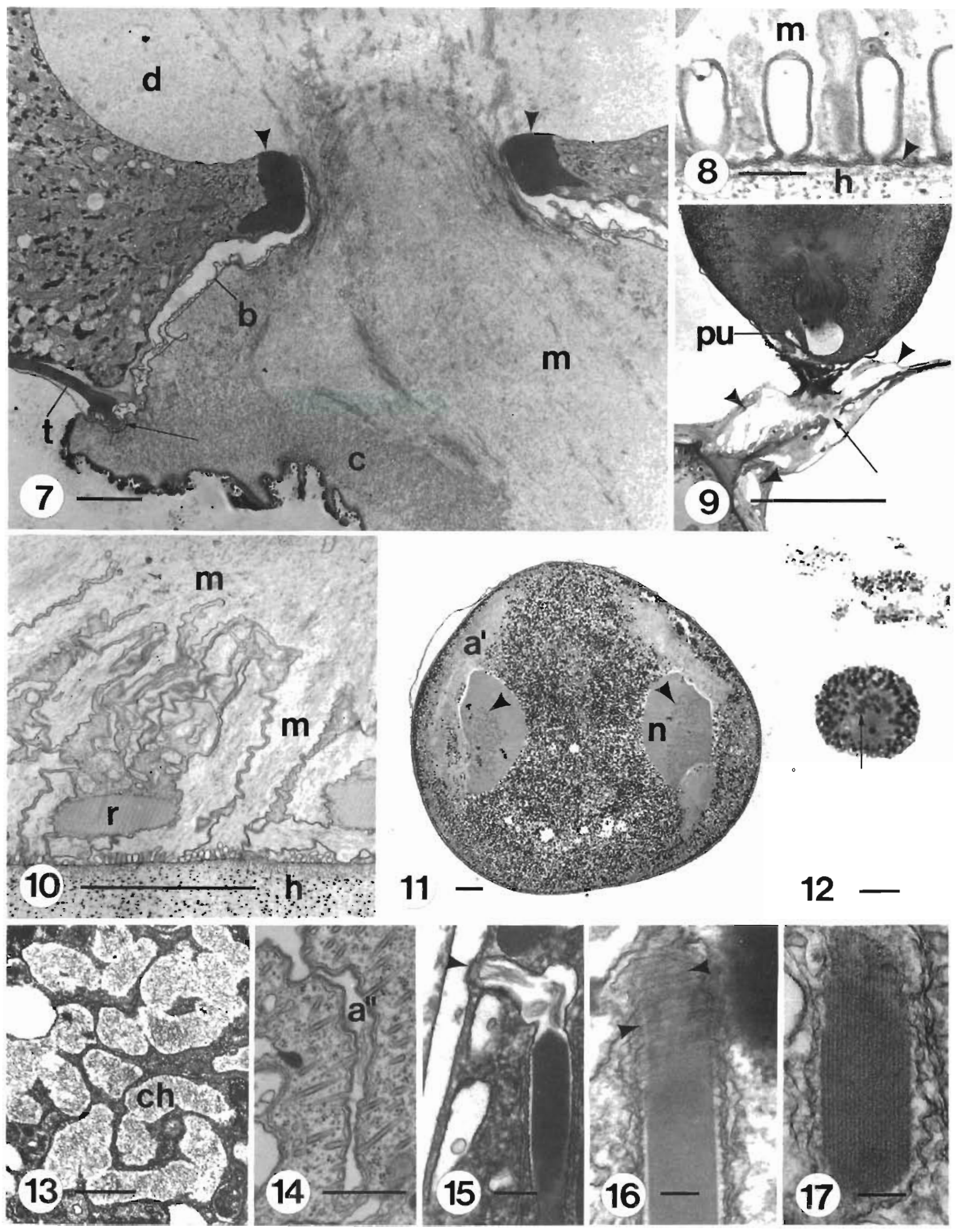

12

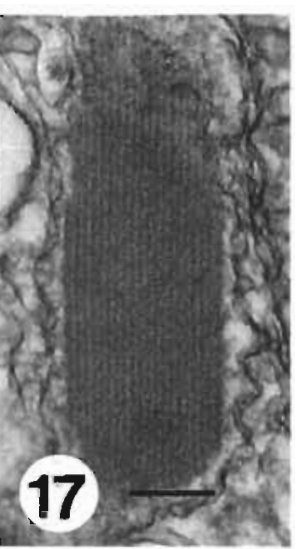


Sagitta elegans parasite were not described for 0 . poucheti, however, and the trophozoite of $O$. poucheti is much smaller (180 um).

These differences, together with the differences in host organisms and geographical distribution, lead to our designation of the Sagitta elegans parasite as a new species, Oodinium jordani.

Differences in cell division between species of Oodinium have not been firmly established. Cleavage of the trophozoite is longitudinal (Chatton 1920); chromosomes, visible with LM, appear soon after the parasite leaves the host and prior to the first division in some species (Cachon \& Cachon 1977), as do a pair of archoplasmic masses (well provided with mitochondria in O. jordani, unlike O. fritillariae; Cachon \& Cachon 1977 ) that llank the daughter nuciei; abundant smail nucleoli are present (Hovasse 1935). Division proceeds until a large number of small, biflagellated dinoflagellates or dinospores with typical dinokaryotic chromosomes have been produced (Chatton 1920). In the present study, small cells bearing a stage in the formation of dinoflagellate chromosomes (Cachon \& Cachon 1977) were the products of the 9th division; further divisions probably would produce infective dinospores.

Lipid bodies are a common food reserve in parasitic dinoflagellates. In addition, our specimens contained paraglycogen-like granules that presumably were the uncolored refringent inclusions described in Oodinium poucheti by Chatton (1920). Trichocysts were of the type characteristic of dinoflagellates (McLean et al. 1987 ) and, insofar as we can determine, has not been found in other groups of organisms.

The usual attachment of our specimens of Oodinium jordani to the host fin, rather than to the body, implies that the dinospore chooses its attachment site on a given host. Laboratory observations on the behavior of dinospores in the presence of Sagitta elegans might verify a presumed tendency to choose the fin rather than the body as a site for attachment. Still to be

Responsible Subject Editor: Dr A. K. Sparks, Seattle, Washington, USA elucidated are the specific nutritional requirements of O. jordani trophozoites. At this time, it appears that those requirements are met only by nutrients found within chaetognaths.

Acknowledgements. We are grateful to Dr A. O. Dennis Willows for use of research facilities at the Friday Harbor Laboratories, University of Washington, to Dr Colin Hermans and Christopher Jordan for supplying us with parasitized hosts, and to Dr George Shinn for valuable comments. We are indebted to Professor Jean Cachon and Mme. Monique Cachon for their interest in this study. The second author's stay at Friday Harbor was made possible by a grant from the Danish Natural Science Research Council

\section{LITERATURE CITED}

Cachon, J. (1964). Contribution à l'étude des Péridiniens parasites. Cytologie, cycles évolutifs. Ann. Sci. Nat., Zool. Paris, 12 Sér. 6: 1-158

Cachon, J., Cachon, M. (1971). Ultrastructures du genre Oodinium Chatton. Différenciations cellulaires en rapport avec la vie parasitaire. Protistologica 7: 153-169

Cachon, J., Cachon, M. (1977). Observations on the mitosis and on the chromosome evolution during the lifecycle of Oodinium, a parasitic dinoflagellate. Chromosoma 60: $237-251$

Cachon, J., Cachon, M. (1987). Parasitic dinoflagellates. In Taylor, F. J. R. (ed.) The biology of dinoflagellates. Blackwell Scientific Publications, Oxford, p. 571-610

Cachon, J., Cachon, M., Greuet, C. (1970). Le système pusulaire de quelques Péridiniens libres ou parasites. Protistologica 6: 467-476

Chatton, E. (1912). Diagnoses préliminaires de Péridiniens parasites nouveaux. Bull. Soc. Zool. Fr. 37: 85-93

Chatton, E. (1920). Les Péridiniers parasites. Morphologie reproduction, ethologie. Arch. Zool. exp. gén. 59: 1-475

Dogiel, V. (1910). Untersuchungen über einige neue Catenata. Z. wiss. Zool. 94: 400-446

Hovasse, R. (1935). Deux Péridiniens parasites convergents: Oodinium poucheti (Lemm.), Protoodinium chattoni gen nov. sp. nov. Bull. biol. Fr. Belg. 69: 59-86

McLean, N., Hochberg, F. G., Shinn, G. L. (1987). Giant protistan parasites on the gills of cephalopods (Mollusca). Dis. aquat. Org. 3: 119-125

Manuscript first received: May 30, 1989

Revised version accepted: July 26, 1989 